\title{
Cotransformation and Gene Targeting in Mouse Embryonic Stem Cells
}

\author{
LAURA H. REID, ${ }^{*}$ EDWARD G. SHESELY, HYUNG-SUK KIM, AND OLIVER SMITHIES \\ Department of Pathology, University of North Carolina, Chapel Hill, North Carolina 27599
}

Received 29 October 1990/Accepted 15 February 1991

\begin{abstract}
We have investigated cotransformation in mammalian cells and its potential for identifying cells that have been modified by gene targeting. Selectable genes on separate DNA fragments were simultaneously introduced into cells by coelectroporation. When the introduced fragments were scored for random integration, $75 \%$ of the transformed cells integrated both fragments within the genome of the same cell. When one of the cointroduced fragments was scored for integration at a specific locus by gene targeting, only $4 \%$ of the targeted cells cointegrated the second fragment. Apparently, cells that have been modified by gene targeting with one DNA fragment rarely incorporate a second DNA fragment. Despite this limitation, we were able to use the cotransformation protocol to identify targeted cells by screening populations of colonies that had been transformed with a cointroduced selectable gene. When hypoxanthine phosphoribosyltransferase (hprt) targeting DNA was coelectroporated with a selectable neomycin phosphotransferase (neo) gene into embryonic stem (ES) cells, hprt-targeted colonies were isolated from the population of neo transformants at a frequency of 1 per 70 G418-resistant colonies. In parallel experiments with the same targeting construct, hprt-targeted cells were found at a frequency of 1 per 5,500 nonselected colonies. Thus, an 80-fold enrichment for targeted cells was observed within the population of colonies transformed with the cointroduced DNA compared with the population of nonselected colonies. This enrichment for targeted cells after cotransformation should be useful in the isolation of colonies that contain targeted but nonselectable gene alterations.
\end{abstract}

Gene targeting by homologous recombination is a powerful tool for creating planned alterations at chromosomal loci. It has been used in mammalian cells both to inactivate specific genes $(14,17,26,36)$ and to correct characterized mutations $(1-3,5)$. When such alterations are made in embryonic stem (ES) cells, the planned changes can be transferred to the mouse germ line after blastocyst injection $(12,13,25,31,36)$. However, since homologous recombination is a rare event in mammalian cells, the identification of a targeted cell within a pool of nontargeted cells can be difficult. In previous experiments, targeted cells were identified by a selectable alteration in the activity of the target gene $(1-3,5,6)$ and/or by including a selectable gene in the targeting DNA $(17,28,30)$. This second, enrichment technique enables one to eliminate the majority of cells which are not transformed since only the colonies that contain the targeting DNA are screened for its incorporation at the target locus. However, these techniques are limited because few genes are directly selectable in vitro and because the enrichment method is restricted to alterations that are compatible with the insertion of a selectable gene into the target locus. To create subtle alterations without leaving selectable sequences in the target gene, new enrichment methods must be developed to assist in identifying targeted cells from the mass of nontransformed and nontargeted cells.

Several investigators have reported that cells simultaneously transformed with two unlinked DNA fragments often integrate both fragments into their genome $(4,21,24$, 32-34). This cotransformation procedure has been used to isolate cells that have incorporated nonselectable exogenous DNA by screening a population of cells transformed with a

\footnotetext{
* Corresponding author.
}

cointroduced selectable sequence $(15,19)$. The same protocol might be useful in gene targeting. If the targeting DNA was cointroduced with an unrelated selectable gene, a high proportion of the cells that integrated the selectable gene might also contain the targeting DNA, possibly integrated at the target locus. Thus, targeted cells could be enriched in the cotransformed population without requiring the creation of a selectable alteration at the target locus.

In this report, we describe the results of investigations of cotransformation in mammalian cells to determine its potential in gene-targeting experiments. On the basis of previous experiments by our laboratory (4) and others (33), we expected to observe the independent integration of the targeting DNA and the selectable gene after their coelectroporation. The selectable gene was not expected to interfere with targeted recombination and should be separable from the targeted locus by appropriate matings after the cotransformed ES cells were established in the mouse germ line. However, after examining cotransformation in fibroblasts and mouse ES cells, we observed a discrepancy in the pattern of DNA integration between targeted and nontargeted cells. Although cotransformation was frequently observed in nontargeted cells, ES cells with targeted gene alterations rarely integrated a second DNA molecule. In addition, DNA that integrated by nonhomologous recombination was often present as concatemers at multiple sites within the genome, whereas DNA that integrated by homologous recombination was observed in single copy at the target locus. Despite these differences, we were able to demonstrate an 80-fold enrichment for targeted cells within a population of colonies transformed with a cointroduced selectable gene, thereby establishing the usefulness of cotransformation as an enrichment technique in some genetargeting experiments. 


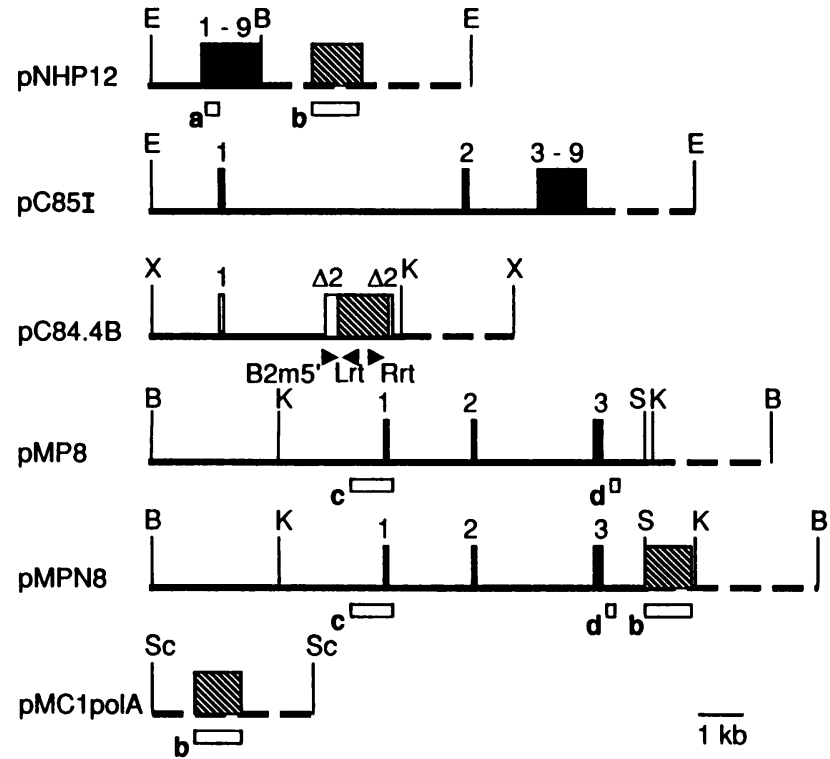

FIG. 1. Structures of the plasmids used in these cotransformation studies. Boxes represent exons; solid lines represent genomic DNA; dashed lines represent bacterial vector sequences. Symbols: $\square$, hprt DNA; $\square, \beta_{2} m$ DNA; $\$$, the neo gene. Regulatory sequences are described in Materials and Methods, but are not depicted here. Plasmids pMP8 and pMPN8 contain a mixture of mouse- and human-derived hprt genomic DNA. Also, part of intron 1 in plasmid pC85I has been deleted. Restriction enzyme sites used for linearization and Southern blot analysis are indicated: B, BamHI; E, EcoRI; K, KpnI; S, SalI; Sc, ScaI; X, XhoI. DNA fragments used as probes are illustrated below each line: $\mathrm{a}, 0.3-\mathrm{kb}$ XhoI-HindIII human hprt cDNA fragment; b, 1.1-kb XhoI-SalI neo fragment; c, 1.0-kb SmaI human hprt genomic fragment; d, 0.2-kb RsaI mouse hprt genomic fragment. Arrowheads represent some of the primers used in PCR analysis.

\section{MATERIALS AND METHODS}

Cells and tissue culture. GM0847 is a hypoxanthine phosphoribosyltransferase (HPRT)-deficient, simian virus 40transformed human fibroblast line obtained from the $\mathrm{Na}$ tional Institute of General Medical Sciences Human Genetic Mutant Cell Repository. Cells from this line were grown in Dulbecco modified Eagle medium supplemented with $10 \%$ fetal calf serum. E14TG2a is an HPRT ${ }^{-}$ES cell line obtained from Martin Hooper (9). This cell line was grown on embryonic-fibroblast feeder layers as previously described (7).

Electroporation. Cells were electroporated in the electrode chamber as previously described (4). GM0847 cells were suspended in growth medium to $10^{7}$ cells per ml. A $0.5-\mathrm{ml}$ portion of the cell suspension was mixed with linearized DNA (5 $\mathrm{nM}$ for each of the cotransformed fragments). This suspension was immediately exposed at room temperature to an electric pulse from a $14-\mu \mathrm{F}$ capacitator charged to 500 V. Approximately $5 \times 10^{4}$ electroporated cells were plated in $100-\mathrm{mm}$ dishes containing growth medium. At $24 \mathrm{~h}$ after electroporation, the growth medium was replaced with medium containing either G418 $(400 \mu \mathrm{g} / \mathrm{ml})$, HAT $(120 \mu \mathrm{M}$ hypoxanthine, $0.4 \mu \mathrm{M}$ aminopterin, $20 \mu \mathrm{M}$ thymidine), or G418 plus HAT. E14TG2a cells were electroporated in a similar manner, except that the $0.5-\mathrm{ml}$ cell-DNA suspension contained between $2.5 \times 10^{7}$ and $5 \times 10^{7}$ cells and the electric pulse was from a 200 - to $250-\mu \mathrm{F}$ capacitator charged to $300 \mathrm{~V}$. Electroporated E14TG2a cells were grown in either
TABLE 1. Cotransformation frequency in human fibroblasts

\begin{tabular}{|c|c|c|c|c|}
\hline \multirow{2}{*}{ Expt } & \multicolumn{3}{|c|}{$\begin{array}{l}\text { Transformation frequency (per } 10^{5} \\
\text { electroporated cells) }^{a}\end{array}$} & \multirow{2}{*}{$\begin{array}{c}\text { Cotransformation } \\
\text { frequency }(\%) \\
\left(\mathrm{HAT}^{\mathrm{r}} \mathrm{G}^{2} 18^{\mathrm{r}} / \mathrm{HAT}^{r}\right)\end{array}$} \\
\hline & $\begin{array}{l}\text { HAT }^{r} \\
\text { colonies }\end{array}$ & $\begin{array}{l}\mathrm{G}^{\prime} 18^{\mathrm{r}} \\
\text { colonies }\end{array}$ & $\begin{array}{l}\text { HAT }^{\mathrm{r}} \mathrm{G} 418^{\mathrm{r}} \\
\text { colonies }\end{array}$ & \\
\hline 1 & 43 & 93 & 35 & 81 \\
\hline 2 & 48 & 99 & 48 & 100 \\
\hline 3 & 34 & 79 & 44 & 129 \\
\hline 4 & 84 & 121 & 82 & 98 \\
\hline Mean & 52 & 98 & 52 & 102 \\
\hline
\end{tabular}

${ }^{a}$ Colonies obtained after coelectroporating the neo and hprt fragments from plasmid pNHP12 digested with BamHI and EcoRI into GM0847 cells.

G418 $(200 \mu \mathrm{g} / \mathrm{ml})$, HAT, G418 plus HAT, or nonselective medium. The cell densities were approximately $5 \times 10^{6}$ cells per dish for HAT selection, $2.5 \times 10^{6}$ cells per dish for G418 selection, and $1 \times 10^{5}$ cells per dish for no selection.

Plasmid construction. The following plasmids were used in our studies and are illustrated in Fig. 1. pNHP12 contains the human hprt cDNA driven by a Moloney murine sarcoma virus long terminal repeat and the neomycin phosphotransferase (neo) gene attached to simian virus 40 promoter, intron, and polyadenylation sequences. It was constructed by ligating the 4.9-kb BamHI-EcoRI neo fragment from pSV2neo (29) to a 2.6-kb EcoRI-BamHI hprt fragment from p4ALTR, a derivative of the hprt cDNA plasmids pLpL (18) and $\mathrm{p} 4 \mathrm{aA} 8(10)$. $\mathrm{pC} 85 \mathrm{I}$ is a human hprt expression vector that contains genomic DNA extending from the hprt promoter through intron 2 and cDNA for exons 3 through 9 . It was constructed after modification of the ClaI site in p4aA8 (10) to an EcoRI site by treatment with Klenow fragment and addition of EcoRI linkers (New England BioLabs). The 3.4-kb HindIII-EcoRI cDNA fragment from this modified plasmid was then ligated to the 9.5-kb EcoRI-HindIII genomic DNA fragment from pHP5 (22). pMC1polA (Stratagene) is a neo expression vector (30) driven by the thymidine kinase promoter and the mutant polyomavirus enhancer PyF441 (16). pC84.4B is a $\beta_{2}$-microglobulin $\left(\beta_{2} m\right)$ targeting construct that contains the neo gene from pMClpolA inserted into exon 2 of a $\beta_{2} m$ gene fragment (14). pMP8 is an hprt targeting construct designed specifically to correct the hprt deletion in E14TG2a cells. It contains $4 \mathrm{~kb}$ of mouse genomic DNA $5^{\prime}$ to the deletion, $1.8 \mathrm{~kb}$ of human hprt genomic DNA including the promoter and exon 1 , and $7 \mathrm{~kb}$ of mouse hprt genomic DNA including exons 2 and 3 (see Fig. 3). pMPN8 is an hprt targeting construct that also contains the neo gene. It was constructed by inserting the 1.1-kb XhoI-SalI neo fragment from pMC1polA into the SalI site in the vector sequences of pMP8. The BamHI site in the neo insert was removed by treatment with Klenow fragment.

DNA isolation and Southern blot hybridization. Genomic DNA was isolated from cultured cells by using conventional methods. DNA was digested, separated on $0.8 \%$ agarose gels, transferred to nylon membranes, and hybridized with ${ }^{32} \mathrm{P}$-labeled probes. The locations of the probes are shown in Fig. 1.

PCR. Approximately $10^{4}$ cells were pelleted, resuspended in $5 \mu$ l of phosphate-buffered saline (PBS), lysed with $30 \mu l$ of water, and treated with proteinase $\mathrm{K}$ as described previously (11). One-third to one-half of the lysis solution was amplified in $50 \mu \mathrm{l}$ with polymerase chain reaction (PCR) buffer $\left[1.5 \mathrm{mM} \mathrm{MgCl}_{2}, 67 \mathrm{mM}\right.$ Tris (pH 8.8), $17 \mathrm{mM}$ 


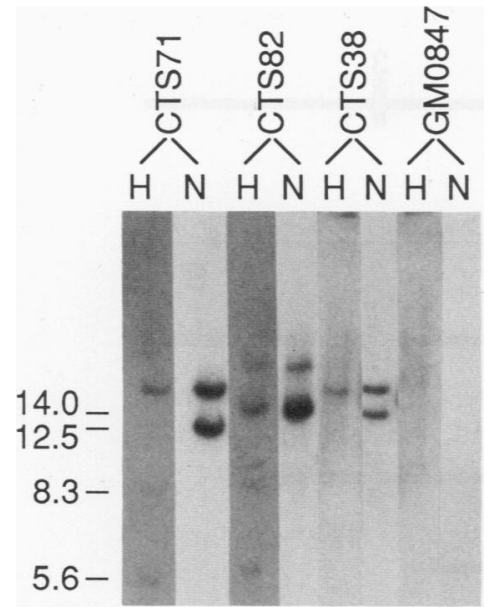

FIG. 2. Genome analysis of fibroblasts cotransformed with hprt and neo DNA. Southern blots hybridized with either the 0.3-kb XhoI-HindIII human hprt cDNA probe (lanes $\mathrm{H}$ ) or the $1.1-\mathrm{kb}$ XhoI-SalI neo probe (lanes N). The lanes contain $5 \mu \mathrm{g}$ of $\mathrm{XbaI}$ digested genomic DNA from the parental fibroblast line GM0847 or from three colonies, CTS71, CTS82, and CTS38, cotransformed with the hprt and neo fragments derived from pNHP12. (Subsequent hybridization of this blot to a $\beta$-globin IVS2 probe proved that these genomic digests were complete.) The sizes (in kilobase pairs) of some of the genomic bands are indicated.

$\left(\mathrm{NH}_{4}\right)_{2} \mathrm{SO}_{4}, 10 \mathrm{mM} \beta$-mercaptoethanol, $7 \mu \mathrm{M}$ EDTA, $50 \mathrm{ng}$ of bovine serum albumin per $\mathrm{ml}$ ] including $0.25 \mu \mathrm{g}$ of each primer, $1.5 \mathrm{U}$ of TaqI polymerase, and $0.2 \mathrm{mM}$ each deoxyribonucleotide. The mixture was exposed to 55 cycles of 65 $\mathrm{s}$ at $92^{\circ} \mathrm{C}$ followed by $7 \mathrm{~min}$ at $65^{\circ} \mathrm{C}$. Some of the positions of the PCR primers are shown in Fig. 1 (see also reference 14). Their sequences are listed below: $\beta_{2} \mathrm{~m} 5$ ', 5'-GTGGCCCTCA GAAACCCCTC-3'; $\beta_{2} \mathrm{~m}^{\prime}$ ', 5'-GATGCTGATCACATGTC TCG-3'; Lrt, 5'-TGCGCTGACAGCCGGAACAC-3'; Rrt, 5'-TGGCGGACCGCTATCAGGAC-3'.

\section{RESULTS}

Cotransformation frequency in human fibroblasts. In our studies of cotransformation in cultured cells, we used two selectable genes, hprt and neo, which, when expressed in the cell, confer resistance to HAT and G418, respectively. Previous cotransformation studies have introduced similar selectable markers on two separate plasmids $(4,32,33)$. Homologous recombination between the vector sequences common to these cointroduced plasmids might create concatemers that could integrate into the genome as one molecule and consequently artificially increase the frequency of cotransformed cells. To eliminate the possibility of this type of homologous recombination, we electroporated cells with an equimolar mixture of the selectable genes on separate, nonhomologous fragments.

The plasmid pNHP12 contains both a human hprt cDNA driven by a Moloney murine sarcoma virus long terminal repeat promoter and a neo gene attached to simian virus $\mathbf{4 0}$ promoter, intron, and polyadenylation sequences. It was cut into two fragments, one containing the neo gene and the other containing the hprt gene, which were then cointroduced into the HPRT ${ }^{-}$human fibroblast line GM0847 by electroporation. Treated cells were selected in medium containing either HAT, G418, or HAT plus G418. The frequency of resistant colonies obtained under each selective
TABLE 2. Cotransformation frequency in nontargeted ES cells

\begin{tabular}{lccccc}
\hline Expt & $\begin{array}{c}\text { No. of } \\
\text { electro- } \\
\text { porated } \\
\text { cells }\left(10^{7}\right)\end{array}$ & $\begin{array}{c}\text { No. of HAT } \\
\text { colonies }^{a} \\
\text { (nontargeted) }\end{array}$ & $\begin{array}{c}\text { No. of HAT } \\
\text { colonies ex- } \\
\text { amined by }^{\mathbf{P}} \text { PCR }^{b}\end{array}$ & $\begin{array}{c}\text { No. of HAT } \\
\text { colonies with } \\
\text { neo DNA }\end{array}$ & $\begin{array}{c}\text { Cotrans- } \\
\text { formation } \\
\text { frequency } \\
(\%)^{c}\end{array}$ \\
\hline 1 & 2.5 & 762 & 50 & 37 & 74 \\
2 & 2.5 & 523 & 24 & 19 & 79 \\
Total & 5.0 & 1,285 & 74 & 56 & 76 \\
\hline
\end{tabular}

${ }^{a}$ Colonies obtained after coelectroporating the hprt nontargeting plasmid pC85I digested with EcoRI and plasmid pC84.4B digested with $\mathrm{XhoI}$ and $\mathrm{KpnI}$ into E14TG2a cells.

${ }^{b} \mathrm{PCR}$ analysis performed with the primers $\beta_{2} \mathrm{m5}$ ' and Lrt to identify nontargeted integration of the pC84.4B DNA.

c Percentage of HAT ${ }^{r}$ colonies examined by PCR that also contain the neo DNA.

condition is shown in Table 1 . Individual colonies were grown for further analysis.

The cotransformation frequency of the hprt and neo fragments was determined by two methods. In the first method, this value was calculated as the frequency of doubly selected colonies (both HAT and G418 resistant) divided by the frequency of singly selected colonies (HAT or G418 resistant). The average frequency of transformation for the hprt fragment (52 HAT-resistant colonies per $10^{5}$ electroporated cells) was lower than that obtained for the neo fragment (98 G418-resistant colonies per $10^{5}$ electroporated cells) (Table 1). Since the double-resistance frequency cannot be higher than the lower of the two single-resistance frequencies, we used the hprt transformation frequency as the denominator in our cotransformation calculations. Using this method, we computed the frequency of cotransformation as approximately $100 \%( \pm 20 \%)$. In the second method of estimating cotransformation, we calculated the frequency as the fraction of colonies isolated from a single selection method that could then survive the alternative selection method. Of the 12 HAT-resistant colonies examined, 9 were also resistant to G418. Likewise, of the 14 G418-resistant colonies analyzed, 10 were also resistant to HAT. This method leads to a cotransformation frequency of $75 \%$. These frequencies indicate that a high proportion of the electroporated fibroblasts integrate and express both of the cointroduced genes.

Genome analysis of cotransformed cells. The genomic arrangement of the cointroduced fragments was determined for a number of individual colonies by Southern blot analysis. Genomic DNA isolated from fibroblast colonies resistant to both HAT and G418 was digested with $\mathrm{XbaI}$, which does not cut within either of the introduced fragments. Blots of these genomic digests were consecutively hybridized with the 0.3-kb XhoI-HindIII hprt probe and the 1.1-kb XhoI-SalI neo probe (labeled a and $b$ in Fig. 1). Common bands, which hybridize to both the neo probe and the hprt probe, indicate genomic sites where both fragments have integrated together as a concatemer. Unique bands, which hybridize to the hprt probe or to the neo probe alone, indicate genomic sites where only one fragment type has integrated, in either single or multiple copies. The number of hybridizing bands reveals the number of plasmid integration sites. A representative blot for three cotransformed colonies is shown in Fig. 2. Bands unique for neo hybridization are seen at $14 \mathrm{~kb}$ in colony CTS38 and at $12.5 \mathrm{~kb}$ in colony CTS71. Bands unique for $h p r t$ hybridization are observed at approximately 8.3 and $5.6 \mathrm{~kb}$ in colonies CTS71 and CTS82. Common bands of 

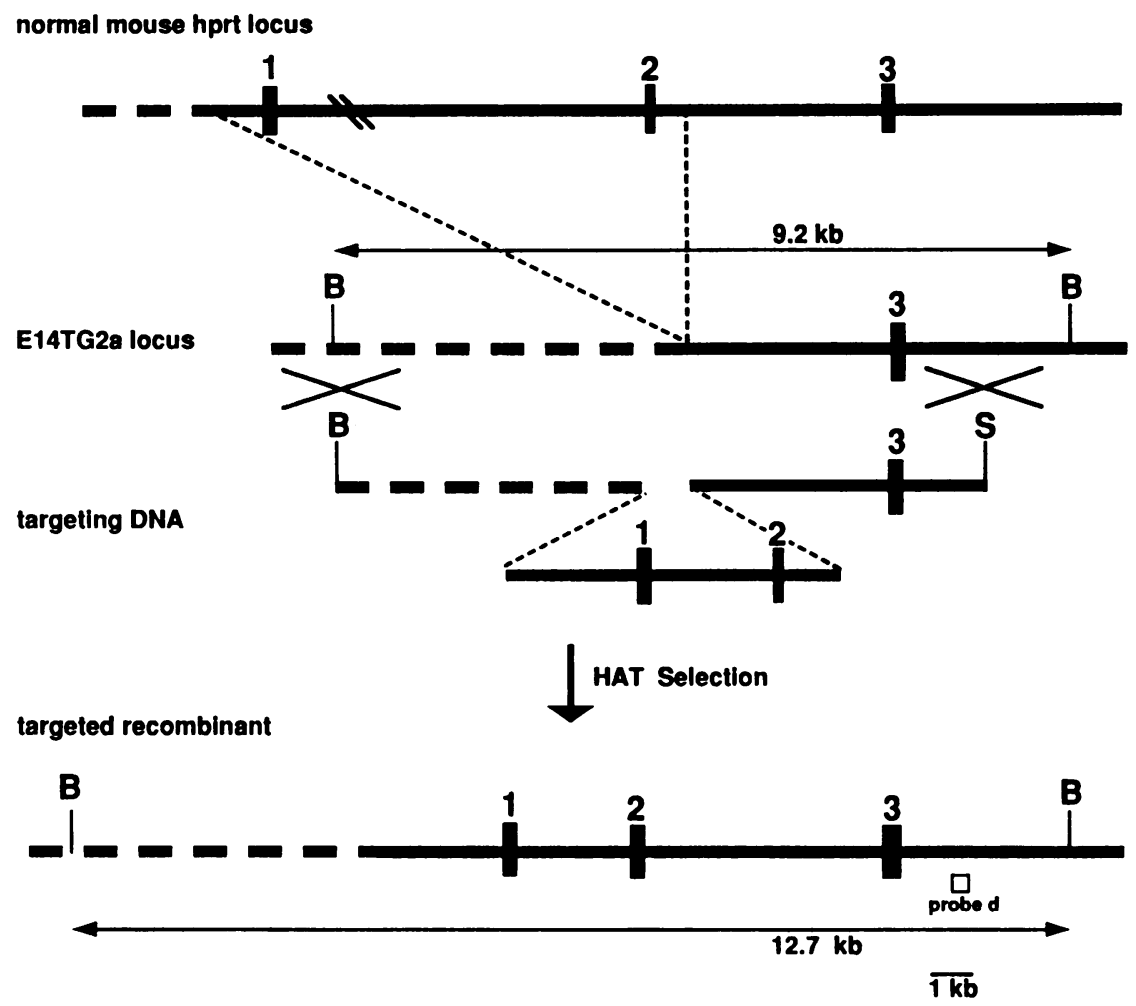

FIG. 3. Targeting design for the hprt locus in E14TG2a cells. The structures of the first three exons of the normal mouse hprt locus, the E14TG2a deletion locus, and the targeted recombinant locus are illustrated. Boxes represent exons; solid lines represent introns; dashed horizontal lines represent sequences normally several kilobase pairs upstream of the hprt locus. Diagonal solid lines indicate that this area of the normal mouse hprt locus is not drawn to scale. The promoter and exon 1 sequences in the targeting DNA and recombinant locus are derived from the human hprt gene. The BamHI (B) and Sall (S) restriction enzyme sites used to linearize the targeting DNA are indicated. The origin of the 0.2-kb RsaI mouse hprt genomic probe (d) and the diagnostic BamHI fragments used for genome analysis are shown.

more than $14 \mathrm{~kb}$, which hybridize to both probes, are observed in each of the three colonies. No neo or hprt hybridizing bands (including those from the endogenous hprt locus) were detected under these hybridization conditions in the parental cell line, GM0847.

Of 43 cotransformed colonies analyzed in this manner, 6 contained a single common band, suggesting the integration of both fragments together at only one site in the genome. The remaining 37 colonies showed multiple sites of DNA integration (average number of integration sites per genome, 3.0 ; range, 1 to 7 sites). Of the 37 colonies, 5 had only unique bands, suggesting integration of each plasmid type at separate sites in the genome. The remaining 32 colonies had either multiple common bands or a combination of both common and unique bands, like those illustrated in Fig. 2. These data suggest the frequent formation of concatemers of the $h p r t$ and/or neo fragments. Indeed, $50 \%$ of the genomic bands hybridized to both the neo and hprt probes. The frequency of concatemers is probably larger than this number suggests, since unique bands that hybridize to either the neo or the hprt probe alone may contain multiple copies of one fragment type. These results indicate that under these electroporation conditions, cotransformed colonies usually integrate concatemers of the introduced fragments at several sites in the genome.

Cotransformation frequency in nontargeted mouse ES cells. The frequency of cotransformation in mouse ES cells was also determined by using hprt and neo gene constructs different from those introduced in the fibroblast experi- ments. Plasmid pC85I contains the human hprt promoter and coding DNA as well as regulatory elements in the first two introns of the gene that are required for its efficient expression in ES cells (22). Plasmid pC84.4B contains the neo gene driven by the thymidine kinase promoter and the mutant polyomavirus enhancer PyF441 (16) that increase its expression in ES cells. This plasmid also contains mouse $\beta_{2} m$ gene sequences (described below).

DNA fragments containing either the neo or hprt gene, excised from these plasmids so that they have no sequences in common, were cointroduced into the HPRT ${ }^{-}$ES cell line E14TG2a. Electroporated cells were selected in HAT medium. Resistant colonies were individually examined by PCR analysis for the presence of the neo fragment, which can be detected by the amplification of a 610 -bp fragment between the $\beta_{2} \mathrm{~m}^{\prime}$ and Lrt primers (Fig. 1). The frequency of cotransformation was calculated as the proportion of HAT-resistant ES cell colonies that had integrated (but not necessarily expressed) the neo DNA. hprt transformants were observed at a frequency of approximately 1 per $4 \times 10^{4}$ electroporated cells (Table 2). Approximately $75 \%$ of these HAT-resistant colonies were cotransformed. This value is essentially the same as that observed in the fibroblast cells and indicates that ES cells also frequently integrate both copies of the coelectroporated DNA.

Cotransformation frequency in targeted mouse ES cells. In the foregoing cotransformation tests, both of the introduced fragments were scored for random integration into the cellular genome by nonhomologous recombination. We next 
TABLE 3. Cotransformation frequency in targeted ES cells

\begin{tabular}{lccccc}
\hline Expt & $\begin{array}{c}\text { No. of } \\
\text { electro- } \\
\text { porated } \\
\text { cells }\left(10^{7}\right)\end{array}$ & $\begin{array}{c}\text { No. of HAT } \\
\text { colonies }^{a} \\
\text { (targeted) }\end{array}$ & $\begin{array}{c}\text { No. of HAT } \\
\text { colonies ex- } \\
\text { amined by } \\
\text { PCR }^{b}\end{array}$ & $\begin{array}{c}\text { No. of HAT } \\
\text { colonies with } \\
\text { neo DNA }\end{array}$ & $\begin{array}{c}\text { Cotrans- } \\
\text { formation } \\
\text { frequency }\end{array}$ \\
\hline 1 & 2.5 & 145 & 95 & 5 & $5 \%$ \\
2 & 4.5 & 162 & 18 & 0 & $<5 \%$ \\
Total & 7.0 & 307 & 113 & 5 & $4 \%$ \\
\hline
\end{tabular}

${ }^{a}$ Colonies obtained after coelectroporating the hprt targeting plasmid pMP8 digested with BamHI and Sall and plasmid pC84.4B digested with $\mathrm{XhoI}$ and $K p n I$ into E14TG2a cells.

${ }^{b} \mathrm{PCR}$ analysis performed with the primers $\beta_{2} \mathrm{~m} 5$ ' and Lrt to identify nontargeted integration of the pC84.4B DNA.

${ }^{c}$ Percentage of the HAT ${ }^{\mathrm{T}}$ colonies examined by PCR that also contain the neo DNA.

determined the cotransformation frequency when one of the introduced fragments was scored for integration at a specific genome site by gene targeting. These experiments were performed with the male-derived, HPRT ${ }^{-}$ES cell line E14TG2a (9). In these cells, a spontaneous deletion has removed the promoter, exons 1 and 2 , and an undetermined length of upstream DNA from the single, X-linked hprt locus. The targeting plasmid pMP8 contains $7.6 \mathrm{~kb}$ of homology to this mutant locus, arranged so that recombination between the targeting plasmid and the homologous genomic sequences inserts the missing hprt promoter and exons (Fig. 3). A successful gene-targeting event creates an intact hprt gene and restores hprt activity.

The hprt-targeting DNA from pMP8 and the neo plasmid pC84.4B were coelectroporated into E14TG2a cells. Targeted cells were isolated by their growth in HAT medium and analyzed for the presence of the neo fragment by PCR. Homologous recombination at the hprt locus occurred in approximately 1 per $10^{5}$ electroporated cells (Table 3 ). The correctly targeted genotype of the HAT-resistant cells was confirmed by Southern blot analysis of DNA from two isolated colonies. In the parent E14TG2a cell line, the deletion breakpoint in the mutant hprt locus is contained on a 9.2-kb Bam HI fragment. After introduction of the missing promoter and exons by homologous recombination, the size of this $B a m H I$ fragment should be increased to $12.7 \mathrm{~kb}$. These fragments can be detected in Southern blot analysis by hybridization to a 200-bp RsaI fragment from intron 3 of the mouse hprt gene (labeled $\mathrm{d}$ in Fig. 1 and 3). Both of the HAT-resistant colonies examined contained the 12.7-kb

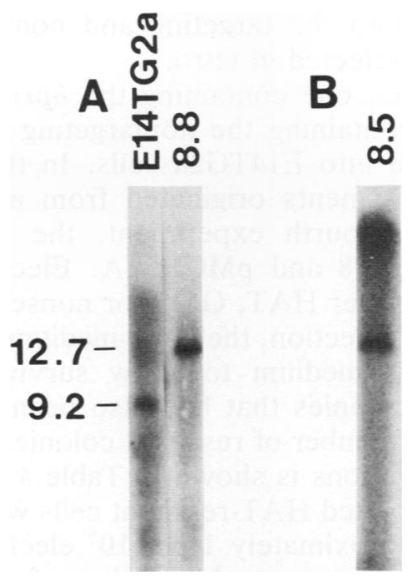

FIG. 4. Genome analysis of ES cell colonies targeted at the hprt locus. The lanes contain $3 \mu \mathrm{g}$ of BamHI-digested genomic DNA from the parental E14TG2a ES cell line or from two illustrative HAT-resistant colonies, 8.5 and 8.8, targeted at the hprt locus after transformation with plasmid pMP8. (A) A Southern blot with E14TG2a and colony 8.8 DNA hybridized with the 0.2-kb RsaI mouse hprt genomic probe. (B) A similar blot with colony 8.5 DNA. The positions of the parental $9.2-\mathrm{kb}$ and recombinant $12.7-\mathrm{kb}$ bands are indicated.

recombinant band in place of the $9.2-\mathrm{kb}$ band seen in the parental cells (Fig. 4). No randomly integrated copies of the hprt DNA were observed.

Surprisingly, PCR analysis revealed that only $4 \%$ of the targeted colonies contained the neo fragment (Table 3). (In another experiment in which G418 resistance was used to identify neo transformed cells, none of $18 \mathrm{hprt}$-targeted colonies contained the cotransformed neo DNA.) This cotransformation frequency in targeted ES cells is at least 20-fold lower than that observed in nontargeted fibroblasts or ES cells. Apparently, cells in which gene targeting has occurred with one DNA sequence are less likely to be cotransformed with a second DNA sequence than are nontargeted cells.

Targeting frequency at the hprt locus in cotransformed cells. Although only $4 \%$ of the targeted cells contained a cointegrant under our conditions of coelectroporation, we still wished to determine whether the cotransformation protocol could be used to help identify targeted cells. To this end, we initiated cotransformation experiments by using a test sys-

TABLE 4. Frequency of hprt targeted colonies in a cotransformed population

\begin{tabular}{|c|c|c|c|c|c|c|c|c|}
\hline Expt & $\begin{array}{l}\text { No. of electroporated } \\
\text { cells under HAT or } \\
\text { no selection }\left(10^{7}\right)\end{array}$ & $\begin{array}{l}\text { No. of non- } \\
\text { selected } \\
\text { colonies } \\
\left(10^{5}\right)^{a}\end{array}$ & $\begin{array}{l}\text { No. of HAT } \\
\text { colonies }^{a} \\
\text { (targeted) }\end{array}$ & $\begin{array}{c}\text { Targeting } \\
\text { frequency }^{b}\end{array}$ & $\begin{array}{l}\text { No. of electro- } \\
\text { porated cells } \\
\text { under } G 418 \\
\text { selection }\left(10^{7}\right)\end{array}$ & $\begin{array}{l}\text { No. of } \\
\text { G418 } \\
\text { colonies }^{a}\end{array}$ & $\begin{array}{l}\text { No. of } \\
\text { HAT }^{r} \\
\text { G418 }^{\mathbf{r}} \\
\text { colonies }^{a}\end{array}$ & $\begin{array}{l}\text { Targeting fre- } \\
\text { quency after } \\
\text { cotransformation }\end{array}$ \\
\hline $\begin{array}{c}1 \\
2 \\
3 \\
4 \\
\text { Mean }^{e}\end{array}$ & $\begin{array}{l}2.5 \\
2.5 \\
1.3 \\
2.5\end{array}$ & $\begin{array}{r}10.0 \\
\mathrm{ND}^{d} \\
3.2 \\
6.6\end{array}$ & $\begin{array}{r}999 \\
64 \\
28 \\
158\end{array}$ & $\begin{array}{l}1 / 1,000 \\
\text { ND } \\
1 / 11,400 \\
1 / 4,200 \\
1 / 5,500\end{array}$ & $\begin{array}{l}2.0 \\
2.3 \\
2.3 \\
\text { ND }\end{array}$ & $\begin{array}{l}156 \\
153 \\
180 \\
\text { ND }\end{array}$ & $\begin{array}{c}2 \\
4 \\
2 \\
\text { ND }\end{array}$ & $\begin{array}{l}1 / 78 \\
1 / 38 \\
1 / 90 \\
\text { ND } \\
1 / 69\end{array}$ \\
\hline
\end{tabular}

a Colonies obtained in experiments 1, 2, and 4 after coelectroporating the hprt targeting and neo nontargeting fragments from plasmid pMPN8 digested with BamHI and Sall into E14TG2a cells. Colonies obtained in experiment 3 after coelectroporating the hprt targeting plasmid pMP8 digested with BamHI and SalI and the neo nontargeting plasmid pMC1polA digested with ScaI into E14TG2a cells.

${ }^{b}$ Ratio of HAT ${ }^{r}$ colonies to nonselected colonies.

${ }^{c}$ Ratio of HAT $^{r} \mathbf{G}^{4} 18^{r}$ Colonies to G418 ${ }^{r}$ Colonies.

${ }^{d}$ ND, Not determined.

e Means were calculated by averaging the ratios from each experiment. 
tem in which both the targeting and nontargeting events could be easily selected in vitro.

Two fragments, one containing the hprt targeting DNA and the other containing the nontargeting neo gene, were coelectroporated into E14TG2a cells. In the three experiments, these fragments originated from a single plasmid pMPN8. In the fourth experiment, the fragments were excised from pMP8 and pMC1polA. Electroporated cells were grown in either HAT, G418, or nonselective medium. After 10 days of selection, the G418 medium was changed to G418 plus HAT medium to allow survival of only the G418-resistant colonies that had also been targeted at the hprt locus. The number of resistant colonies observed from these electroporations is shown in Table 4. As in previous experiments, targeted HAT-resistant cells were isolated at a frequency of approximately 1 per $10^{5}$ electroporated cells. Nonselected colonies were observed at a frequency of 1 per 30 electroporated cells, suggesting a survival and plating efficiency in these experiments of approximately 3\%. By dividing the number of HAT-resistant targeted colonies by the number of nonselected colonies, we estimated that the frequency of targeted cells within the nonselected population varied from $1 / 1,100$ to $1 / 11,400$, with a mean of approximately 1 targeted colony per 5,500 nonselected colonies. This value indicates the number of colonies one would need to screen to identify a targeted cell in the absence of any enrichment or selection methods. G418-resistant cells were isolated at a frequency of 1 per $10^{5}$ electroporated cells. Consecutive selection revealed that 8 of the 489 G418resistant colonies examined were also HAT resistant. These colonies are independent since they were isolated from eight separate tissue culture plates. Thus, approximately $1 \mathrm{hprt}$ targeted colony was identified per 70 G418-resistant colonies. Targeted cells can therefore be identified within a population of colonies transformed with cointroduced DNA at a frequency approximately 80 -fold greater than that observed within a nonselected population (1 targeted colony per 5,500 nonselected colonies versus 1 targeted colony per 69 colonies selected for the cotransformed DNA).

Genome analysis of the targeted and cotransformed cells. The arrangement of the nontargeted DNA in the eight targeted and cotransformed colonies was determined by Southern blot analysis with the 1.1-kb XhoI-SalI neo probe from pMC1polA and with the 1.0-kb $S m a I$ probe from human hprt genomic DNA (labeled b and c in Fig. 1). Southern blots obtained after digesting genomic DNA with KpnI and hybridization to either the neo or hprt probe revealed bands of the types expected from insertions of the cointroduced fragments in various concatemeric arrangements. Figure 5A illustrates the results with four different targeted and cotransformed colonies. The likely origins of the KpnI bands are presented in Fig. 5B. In this analysis, the BamHI site in the hprt fragment was chosen as the head of this fragment, while the SalI site denotes the tail. This orientation agrees with the transcriptional sense of the DNA. Correspondingly, for the neo fragment, the SalI site is the head and the BamHI site is the tail.

When the head of one hprt fragment is ligated to the tail of another hprt fragment, an 11.6-kb KpnI band is expected which will hybridize to the hprt probe (Fig. 5B). This 11.6-kb band was observed in all of the targeted and cotransformed colonies examined, indicating the presence of at least one concatemer containing this arrangement of the introduced hprt DNA. A comparable 17.4-kb KpnI band which hybridizes with the hprt probe is predicted when the colonies contain a concatemer with the tail of one hprt fragment
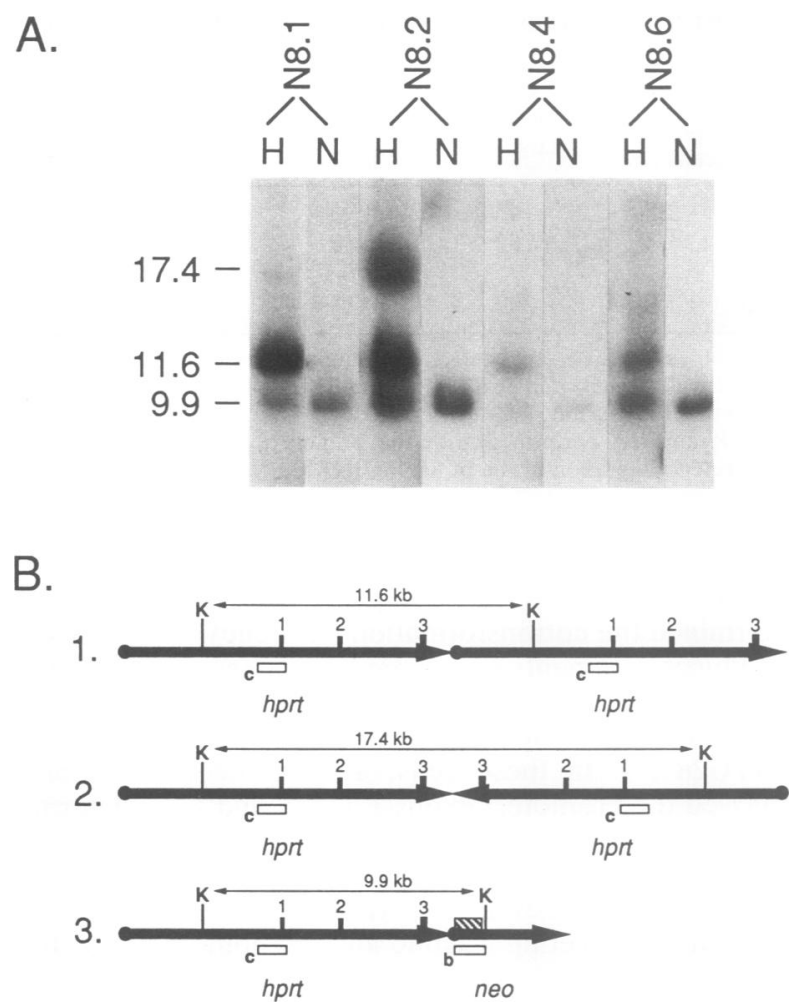

FIG. 5. Genome analysis of ES cell colonies targeted at the hprt locus and cotransformed with neo DNA. (A) Southern blots hybridized with either the 1.0-kb SmaI human hprt DNA probe (lanes $\mathrm{H}$ ) or the 1.1-kb XhoI-SalI neo probe (lanes N). The lanes contain $5 \mu \mathrm{g}$ of KpnI-digested genomic DNA from four HAT- and G418-resistant colonies, N8.1, N8.2, N8.4, and N8.6, cotransformed with the hprt and neo fragments excised from plasmid pMPN8. The sizes (in kilobase pairs) of the diagnostic KpnI bands are indicated. (B) The origins of KpnI bands for three likely concatemeric arrangements between the cointroduced hprt and neo fragments are illustrated. The BamHI site in the hprt fragment and the SalI site in the neo fragment were assigned as the heads of the introduced DNA (0). The SalI site of the hprt fragment and the BamHI site of the neo fragment denote the tails of the DNA $(\triangleright)$. Line 1 illustrates a head-to-tail arrangement of two hprt fragments. Line 2 illustrates a tail-to-tail arrangement of two hprt fragments. Line 3 illustrates a head-to-tail arrangement of an hprt fragment and a neo fragment. Coding sequences are depicted as in Fig. 1.

ligated to the tail of a second hprt fragment. Colonies N8.1 and N8.2 contain this 17.4-kb KpnI band. Concatemers containing both of the introduced fragments are also possible. A 9.9-kb KpnI band is expected when the tail of an hprt fragment is ligated to the head of a neo fragment. This band hybridizes to both the neo and hprt probes. It was observed in all of the targeted and cotransformed colonies examined.

Similar analyses with other enzymes revealed that most of the possible arrangements of the cointroduced fragments were present in all of the colonies examined, although the relative abundance of the concatemers, as deduced from their hybridization intensities, varies between individual targeted and cotransformed colonies. Therefore, under the present electroporation conditions, the DNA that integrates nonhomologously in targeted ES cells is usually present as concatemers. Whether the concatemers are integrated together at one site or individually at several sites scattered throughout the genome has not been determined. Nor have 
we been able to exclude the possibility that some of the concatemers are present at the target locus.

Cotransformation experiments at the $\beta_{2} m$ locus. We next attempted to use cotransformation to identify cells targeted at the $\beta_{2} m$ locus, which is not selectable in vitro. The neo plasmid pC84.4B, introduced in some of the previous ES cell cotransformation experiments, is capable of inactivating the $\beta_{2} m$ locus by inserting neo sequences into exon 2 of this gene during gene targeting (14). Cells targeted with this construct are G418 resistant and yield a 910-bp recombinant fragment after PCR amplification with the two primers Rrt and $\beta_{2} \mathrm{~m}^{\prime}$ (14).

Initially, we looked for $\beta_{2} m$-targeted cells within a population of colonies transformed with co-introduced DNA. To this end, the $\beta_{2} m$ targeting DNA from pC84.4B and the $h p r t$ nontargeting DNA from pC85I were coelectroporated into HPRT $^{-}$E14TG2a ES cells. Nontargeted, HAT-resistant colonies were analyzed for $\beta_{2} m$ targeting by PCR in pools of four or five colonies. No $\beta_{2} m$-targeted colonies were identified among the 596 HAT-resistant colonies screened. Presumably, the enrichment provided by cotransformation was not sufficient to allow the identification of targeted ES cells at this locus within the number of cotransformed colonies screened.

We also attempted to identify $\beta_{2} m$-targeted cells within a population of colonies already known to have been targeted at another locus. For these experiments, the $\beta_{2} m$-targeting DNA from pC84.4B and the hprt-targeting DNA from pMP8 were coelectroporated into E14TG2a cells. Colonies targeted at the hprt locus were isolated by HAT or HAT plus G418 selection and then screened by PCR for a second targeting event at the $\beta_{2} m$ locus. No $\beta_{2} m$-targeted cells were identified among the 455 hprt-targeted colonies examined. Presumably, any enrichment provided by this cotargeting procedure was likewise not sufficient to allow identification of targeted ES cells at this locus within the number of colonies screened.

\section{DISCUSSION}

We have investigated cotransformation in mammalian cells with particular reference to its potential for identifying cells that have been modified by gene targeting. In these experiments, equimolar amounts of two different DNA molecules were cointroduced into cells by electroporation. The frequency with which both molecules cointegrate into the same cell was determined by in vitro cell selection and/or PCR analysis. When both of the introduced molecules were integrated randomly into the genome, a high cotransformation frequency of $75 \%$ was observed in both human fibroblasts and mouse ES cells. In contrast, when the experiment required that one of the introduced molecules was integrated at a specific genome site by gene targeting, the cotransformation frequency was reduced to $4 \%$. Genome analysis of the cotransformed colonies from either type of experiment revealed frequent concatemers of the nonhomologously integrated DNA. Cotransformation and cotargeting protocols were tested for their potential use as an enrichment procedure for identifying targeted cells. Three pairs of fragments were cointroduced: $h p r t$ nontargeting plus $\beta_{2} m$ targeting, hprt targeting plus $\beta_{2} m$ targeting, and neo nontargeting plus hprt targeting. No $\beta_{2} m$-targeted colonies were identified among either 455 hprt-targeted or 596 hprt-nontargeted colonies after coelectroporation of the appropriate pairs of fragments. In contrast, $h p r t$-targeted colonies were isolated in cotransformation experiments at a frequency of approxi- mately 1 per 70 neo transformed colonies. In parallel experiments with the same targeting fragment, hprt-targeted colonies were found at a frequency of approximately 1 per 5,500 nonselected colonies. Thus, an $\mathbf{8 0 - f o l d ~ e n r i c h m e n t ~ f o r ~ h p r t - ~}$ targeted colonies was observed within the neo transformed population as compared with the nonselected population.

Previous studies have examined the cotransformation frequency of two unlinked DNA molecules simultaneously introduced into cultured cells. When the microinjection and calcium phosphate precipitation transformation methods were used, both molecules were incorporated into almost $100 \%$ of the transformed cells $(21,34)$. Similar high frequencies of cotransformation have been observed when electroporation is used to introduce DNA into plant protoplasts (24) and mammalian cells $(32,33)$. We report here a cotransformation frequency of approximately $75 \%$ in both mouse ES cells and human fibroblasts (Tables 1 and 2). This value is not likely to be the consequence of homologous recombination between the two molecules, since the introduced fragments were devoid of overt homology.

A paradoxical but extremely interesting finding from our present work is that targeted cells are approximately 20 -fold less likely to incorporate a second fragment by nonhomologous recombination than are nontargeted cells. Only $4 \%$ of the hprt-targeted colonies incorporated the cointroduced neo DNA (Table 3), compared with $75 \%$ of the hprt-nontargeted colonies in similar electroporation experiments (Table 2). The reduced frequency of cotransformation in targeted cells is also consistent with the absence of randomly integrated copies of the targeting DNA observed in our hprt-targeted (but not cotransformed) colonies (Fig. 4) and in most published targeted cell lines $(3,5,14,28,30)$. Indeed, in the few cases in which more than one copy of the targeting DNA is present in a targeted cell, it is notable that the additional DNA is usually located in a tandem array at the target locus, apparently integrating as part of the original homologous recombination event $(26,31)$. Together, these data indicate that the frequency with which two fragments cointegrate into the same cell is determined in part by the type of recombinational events used for integration, homologous (targeted) or nonhomologous (nontargeted).

This restriction on cotransformation in targeted ES cells could be related to recombination factors dictated by the cell cycle. Wong and Cappechi have reported that the frequency of homologous recombination varies throughout the cell cycle (35). Possibly, when selecting for targeted cells, we isolated a subpopulation of the electroporated cells that were in a cellular state able to execute homologous recombination so effectively that randomly integrated DNA was seldom observed. This explanation suggests that an enrichment for multiple homologous recombination events may be possible in targeted cells. However, such "cotargeted" cells, which had undergone homologous recombination at both the hprt and $\beta_{2} m$ loci, were not observed when targeting plasmids for both of these genes were cointroduced into the same cell. Other factors, such as the topology of the introduced DNA or the existence of discrete enzymatic pathways for homologous versus nonhomologous recombination, may also be responsible for the unusual integration pattern observed in targeted cells.

It is interesting that although DNA fragments incorporated by homologous recombination were observed in single copy at a single site within the genome, DNA fragments that incorporated by nonhomologous recombination were usually present as concatemers at several sites within the same cell. This pattern was observed for the nontargeted DNA in both 
the cotransformed fibroblasts (Fig. 2) and the rare targeted and cotransformed ES cells (Fig. 5). Such concatemers of nonhomologously integrated DNA are common after calcium phosphate (20) and microinjection (8) transformation protocols and have been reported by other investigators after electroporation $(2,3,23)$. In contrast, concatemers were rarely observed in earlier electroporation experiments by Toneguzzo et al. (33) and by Boggs et al. in our laboratory (4). Differences in the electroporation conditions may be responsible for this apparent discrepancy in the integration pattern of the nontargeted DNA. Our current electroporations were performed at $10 \mathrm{nM}$ total DNA $(5 \mathrm{nM}$ each cointroduced fragment), whereas our earlier experiments were done at $2 \mathrm{nM}$. Given that Toneguzzo et al. noted that the frequency of multiple-copy integration increases with the DNA concentration (33), this fivefold increase in DNA concentration seems a likely explanation for the frequent concatemers observed in this report. Future analysis on the relationship between electroporation conditions and the pattern of DNA integration might allow us to alter the transformation protocol to favor single-site integrants in cotransformed colonies.

Using cotransformation, we have identified hprt-targeted cells at a frequency of 1 per 70 neo transformants (Table 4), but no cells targeted at the $\beta_{2} m$ locus were isolated among hprt-transformed colonies. These results are probably related to the different targeting frequencies observed at these loci. Previous experiments have demonstrated that gene targeting at the $\beta_{2} m$ locus occurs at approximately 1 per $2 \times$ $10^{7}$ electroporated cells, a 200 -fold reduction compared with that observed at the hprt locus with the constructs tested (14). Thus, a frequency of 1 targeted colony per 14,000 colonies transformed with the cointroduced DNA would be expected in these $\beta_{2} m$ cotransformation experiments, provided that the level of enrichment is the same as in the hprt experiments $(1 / 70 \times 200)$. At this frequency, our inability to locate $\beta_{2} m$-targeted cells within the 596 hprt transformants examined is not surprising.

The cotransformation protocol we have described has a demonstrated 80-fold enrichment at the hprt locus. Whether this enrichment will be the same at other loci remains to be determined. Recently, Shulman et al. (27) reported cotransformation experiments involving the coelectroporation of an immunoglobulin targeting DNA and a neo gene into hybridoma cells. Their frequency of immunoglobulin-targeted cells in the nonselected population was $5 \times 10^{-6}$; the frequency of G418-resistant colonies was $3 \times 10^{-3}$; and the frequency of immunoglobulin-targeted and G418-resistant colonies was $1.5 \times 10^{-6}$. Although the authors did not analyze their results in this manner, we calculate from their primary data that a 100-fold enrichment was obtained for targeted colonies within the G418-resistant population $\left(1.5 \times 10^{-6} / 3 \times 10^{-3}=\right.$ $\left.5 \times 10^{-4}\right)$ compared with the nonselected population $(5 \times$ $\left.10^{-6}\right)$. This value agrees well with the 80 -fold enrichment we observed in our neo and hprt cotransformation experiments and suggests that the enrichment provided by cotransformation may be similar between different loci and cells.

Although we observe a frequency of 1 targeted cell at the hprt locus per 70 colonies transformed with the cointroduced $n e o$ DNA, it is clear from the $\beta_{2} m$ experiments that this value may be substantially reduced at some loci where gene targeting is less frequent. For this reason, we would not recommend cotransformation for carrying out simple geneinactivation experiments. In such experiments, targeted cells can more easily be identified with the aid of selectable genes on the targeting construct. These procedures can produce a 10,000-fold enrichment for targeted colonies within the selected population, as compared with the nonselected population. However, cotransformation may prove to be useful when more subtle gene modifications are desired or when the introduced selectable genes are not expressed at the target locus. Such targeted but nonselectable cells could currently be identified only by screening every colony that survived electroporation. Since many loci have a targeting frequency of approximately 1 targeted colony per $10^{6}$ surviving cells $(17,26,30,31)$, a nonselective protocol might require the examination of several million colonies. The enrichment provided by cotransformation should reduce this frequency approximately 100 -fold, so that nonselectable targeted cells could be identified within several tens of thousands of colonies transformed with the cointroduced DNA.

In conclusion, our data indicate that a considerable enrichment for targeted cells can be obtained by selection for colonies transformed with a cointroduced gene. This enrichment was observed despite our surprising finding that only a small fraction of the targeted cells incorporate a second DNA molecule. The cotransformation protocol should therefore provide a definite advantage to investigators attempting to isolate cells having targeted but nonselectable gene alterations.

\section{ACKNOWLEDGMENTS}

We appreciate helpful discussions with Beverly Koller and Nobuyo Maeda. We also thank Beverly Koller for the plasmid pC84.4B, PCR primers, some PCR analysis, and assistance with the construction of plasmid pC85I; Kristen Brigman for some PCR analysis; Ron Gregg for assistance with the construction of plasmid pNHP12; Anne Latour and Denise Lee for feeder preparation; and Martin Hooper for the ES cell line E14TG2a.

This work was supported by grants GM20069 and HL37001 from the National Institutes of Health.

\section{REFERENCES}

1. Adair, G. M., R. S. Nairn, J. H. Wilson, M. M. Seidman, K. A. Brotherman, C. MacKinnon, and J. B. Scheerer. 1989. Targeted homologous recombination at the endogenous adenine phosphoribosyltransferase locus in Chinese hamster cells. Proc. Natl. Acad. Sci. USA 86:4574-4578.

2. Baker, M. D. 1989. High-frequency homologous recombination between duplicate chromosomal immunoglobulin $\mu$ heavy-chain constant regions. Mol. Cell. Biol. 9:5500-5507.

3. Baker, M. D., and M. J. Shulman. 1988. Homologous recombination between transferred and chromosomal immunoglobulin $\kappa$ genes. Mol. Cell. Biol. 8:4041-4047.

4. Boggs, S. S., R. G. Gregg, N. Borenstein, and O. Smithies. 1986. Efficient transformation and frequent single site, single copy insertion of DNA can be obtained in mouse erythroleukemia cells transformed by electroporation. Exp. Hematol. 14:988994.

5. Doetschman, T., R. G. Gregg, N. Maeda, M. L. Hooper, D. W. Melton, S. Thompson, and O. Smithies. 1987. Targeted correction of a mutant HPRT gene in mouse embryonic stem cells. Nature (London) 330:576-578.

6. Doetschman, T., N. Maeda, and O. Smithies. 1988. Targeted mutation of the Hprt gene in mouse embryonic stem cells. Proc. Natl. Acad. Sci. USA 85:8583-8587.

7. Doetschman, T. C., H. Eistetter, M. Katz, W. Schmidt, and R. Kemler. 1985. The in vitro development of blastocyst-derived embryonic stem cell lines: formation of visceral yolk sac, blood islands and myocardium. J. Embryol. Exp. Morphol. 87:27-45.

8. Folger, K. R., E. A. Wong, G. Wahl, and M. R. Capechi. 1982. Patterns of integration of DNA microinjected into cultured 
mammalian cells: evidence for homologous recombination between injected plasmid DNA molecules. Mol. Cell. Biol. 2:1372-1387.

9. Hooper, M., K. Hardy, A. Handyside, S. Hunter, and M. Monk. 1987. HPRT-deficient (Lesch-Nyhan) mouse embryos derived from germline colonization by cultured cells. Nature (London) 326:292-295.

10. Jolly, D. J., H. Okayama, P. Berg, A. C. Esty, D. Filpula, P. Bohlen, C. G. Johnson, J. E. Shively, T. Hunkapillar, and T. Friedmann. 1983. Isolation and characterization of a full-length expressible cDNA for human hypoxanthine phosphoribosyltransferase. Proc. Natl. Acad. Sci. USA 80:477-481.

11. Kim, H. S., and O. Smithies. 1988. Recombinant fragment assay for gene targetting based on the polymerase chain reaction. Nucleic Acids Res. 16:8887-8903.

12. Koller, B. H., L. J. Hagemann, T. Doetschman, J. R. Hagaman, S. Huang, P. J. Williams, N. L. First, N. Maeda, and O. Smithies. 1989. Germ-line transmission of a planned alteration made in a hypoxanthine phosphoribosyltransferase gene by homologous recombination in embryonic stem cells. Proc. Natl. Acad. Sci. USA 86:8927-8931.

13. Koller, B. H., P. Marrack, J. W. Kappler, and O. Smithies. 1990. Normal development of mice deficient in $\beta_{2} \mathbf{M}$, MHC class I proteins, and $\mathrm{CD8}^{+} \mathrm{T}$ cells. Science 248:1227-1230.

14. Koller, B. H., and O. Smithies. 1989. Inactivating the $\beta 2$ microglobulin locus in mouse embryonic stem cells by homologous recombination. Proc. Natl. Acad. Sci. USA 86:8932-8935.

15. Kuhn, L. C., A. McClelland, and F. H. Ruddle. 1984. Gene transfer, expression, and molecular cloning of the human transferrin receptor gene. Cell 37:95-103.

16. Linney, E., and S. Donerly. 1983. DNA fragments from F9 PyEC mutants increased expression of heterologous genes in transfected F9 cells. Cell 35:693-699.

17. Mansour, S. L., K. R. Thomas, and M. R. Capecchi. 1988. Disruption of the proto-oncogene int-2 in mouse embryo-derived stem cells: a general strategy for targeting mutations to non-selectable genes. Nature (London) 336:348-352.

18. Miller, A. D., D. J. Jolly, T. Friedmann, and I. M. Verma. 1983. A transmissible retrovirus expressing human hypoxanthine phosphoribosyltransferase (HPRT): gene transfer into cells obtained from humans deficient in HPRT. Proc. Natl. Acad. Sci. USA 80:4709-4713.

19. Newman, R., D. Domingo, J. Trotter, and I. Trowbridge. 1983. Selection and properties of a mouse L-cell transformant expressing human transferrin receptor. Nature (London) 304:643645.

20. Perucho, M., D. Hanahan, and M. Wigler. 1980. Genetic and physical linkage of exogenous sequences in transformed cells. Cell 22:309-317.

21. Pine, D. S., E. C. Bourekas, and S. S. Potter. 1988. Mys retrotransposons in Peromyscus leucopus and transgenic Mus musculus. Nucleic Acids Res. 16:3359-3373.

22. Reid, L. H., R. G. Gregg, O. Smithies, and B. H. Koller. 1990.
Regulatory elements in the introns of the human HPRT gene are necessary for its expression in embryonic stem cells. Proc. Natl. Acad. Sci. USA 87:4299-4303.

23. Riggs, C. D., and G. W. Bates. 1986. Stable transformation of tobacco by electroporation: evidence for plasmid concatenation. Proc. Natl. Acad. Sci. USA 83:5602-5606.

24. Schocher, R. J., R. D. Shillito, M. W. Saul, J. Paszkowski, and I. Potrykus. 1986. Co-transformation of unlinked foreign genes into plants by direct gene transfer. Bio/Technology 4:1093-1096.

25. Schwartzberg, P. L., S. P. Goff, and E. J. Robertson. 1989. Germ-line transmission of a c-abl mutation produced by targeted gene disruption in ES cells. Science 246:799-803.

26. Schwartzberg, P. L., E. J. Robertson, and S. P. Goff. 1990. Targeted gene disruption of the endogenous $c-a b l$ locus by homologous recombination with DNA encoding a selectable fusion protein. Proc. Natl. Acad. Sci. USA 87:3210-3214.

27. Shulman, M. J., L. Nissen, and C. Collins. 1990. Homologous recombination in hybridoma cells: dependence on time and fragment length. Mol. Cell. Biol. 10:4466-4472.

28. Smithies, O., R. G. Gregg, S. S. Boggs, M. A. Koralewski, and R. S. Kucherlapati. 1985. Insertion of DNA sequences into the human chromosomal $\beta$-globin locus by homologous recombination. Nature (London) 317:230-234.

29. Southern, P. J., and P. Berg. 1982. Transformation of mammalian cells to antibiotic resistance with a bacterial gene under control of the SV40 early region promoter. J. Mol. Appl. Genet. 1:327-341.

30. Thomas, K. R., and M. R. Capecchi. 1987. Site-directed mutagenesis by gene targeting in mouse embryo-derived stem cells. Cell 51:503-512.

31. Thompson, S., A. R. Clarke, A. M. Pow, M. L. Hooper, and D. W. Melton. 1989. Germ line transmission and expression of a corrected HPRT gene produced by gene targeting in embryonic stem cells. Cell 56:313-321.

32. Toneguzzo, F., A. C. Hayday, and A. Keating. 1986. Electric field-mediated DNA transfer: transient and stable gene expression in human and mouse lymphoid cells. Mol. Cell. Biol. 6:703-706.

33. Toneguzzo, F., A. Keating, S. Glynn, and K. McDonald. 1988. Electric field-mediated gene transfer: characterization of DNA transfer and patterns of integration in lymphoid cells. Nucleic Acids Res. 16:5515-5532.

34. Wigler, M., R. Sweet, G. K. Sim, B. Wold, A. Pellicer, E. Lacy, T. Maniatis, S. Silverstein, and R. Axel. 1979. Transformation of mammalian cells with genes from procaryotes and eucaryotes. Cell 16:777-785.

35. Wong, E. A., and M. R. Capecchi. 1987. Homologous recombination between coinjected DNA sequences peaks in early to mid-S phase. Mol. Cell. Biol. 7:2294-2295.

36. Zijlstra, M., E. Li, F. Sajjadi, S. Subramani, and R. Jaenisch. 1989. Germ-line transmission of a disrupted $\beta 2$-microglobulin gene produced by homologous recombination in embryonic stem cells. Nature (London) 342:435-438. 